\title{
Is social cohesion relevant to a city in the global South?
}

\section{A case study of Khayelitsha township}

\author{
Vanessa Barolsky \\ vbarolsky@hsrc.ac.za \\ http://dx.doi.org/10.17159/2413-3108/2016/v0n55a753
}

The concept of social cohesion is increasingly being utilised in local and international policy discourse and scholarship. The idea of collective efficacy, defined as 'social cohesion among neighbours combined with their willingness to intervene on behalf of the common good', has been posited as having an important protective effect against violence. This article investigates the relevance of international framings of social cohesion and collective efficacy, which have largely been conceptualised and tested in the global North, to the conditions of social life and violence prevention in a city in the global South. These circumstances are interrogated through an ethnographic study conducted in Khayelitsha township in the Western Cape, where a major internationally funded and conceptualised violence prevention intervention, Violence Prevention through Urban Upgrading (VPUU), has been implemented. The ethnographic material contests some of the key assumptions in international discourses on social cohesion and the manner in which social cohesion has been interpreted and effected in the violence prevention initiatives of the VPUU.

How relevant are prominent Western notions of social cohesion to emerging democratic nation-states? Classic studies on neighbourhood civility focus on the importance of voluntarism and civic participation in local associations. ${ }^{1}$ In a country such as South Africa (in the global South) the question of neighbourliness refers to a different set of challenges that concern surviving poverty and immediate defence of life against imminent violence.

The aim of this article is to understand urban violence in South Africa in the context of local and international engagements, with the concept of social cohesion and collective efficacy as factors that can potentially

\footnotetext{
* Vanessa Barolsky is a research specialist in the Democracy, Governance and Service Delivery Programme (DGSD) at the Human Sciences Research Council.
}

'protect' communities against violence at a neighbourhood level.

The analysis is based on a multi-year international comparative study on the relationship between social cohesion and violence conducted in South Africa and Brazil, funded by the Canadian International Development Research Centre (IDRC) Safe and Inclusive Cities Programme.

This article focuses on the ethnographic material gathered as part of the study during 10 months of fieldwork in the South African township of Khayelitsha in the Western Cape, which experiences high levels of violence and poverty and is the site of a major, internationally funded, violence prevention intervention called 'Violence Prevention through Urban Upgrading' (VPUU). An ethnographic 
methodology was utilised because it allows an understanding of the meanings, beliefs, values and practices of social actors and tries to understand human experience on its own terms, rather than judging it from a normative position. ${ }^{2}$ The article seeks to interrogate formal discourses around social cohesion and violence prevention in relation to an examination of the 'lived' experience of citizens as revealed by the ethnography.

\section{Background}

Social cohesion is a broad concept but generally refers to the factors that 'hold a society together', which has been the focus of philosophical and social inquiry since the time of Aristotle, Aquinas and Montaigne, and in the sociology of Durkheim in the $19^{\text {th }}$ century. Collective efficacy looks at how social cohesion can prevent violence when it is translated into collective action for the 'common good' at neighbourhood level. ${ }^{3}$

Historically, the greatest levels of concern with social cohesion have been at moments of major change, for example during the period of industrialisation, which Durkheim saw as undermining social cohesion. More contemporary challenges and fragmentation associated with globalisation have precipitated a renewed interest in social cohesion as a policy construct from the 1990s.

The concept of social cohesion has been widely used in the international policy environment and has been taken up within forums such as the Organisation for Economic Cooperation and Development (OECD), the European Union (EU), the World Bank, the Club of Rome and the Canadian federal government since the 1990 s.

In South Africa, engagement with the concept through government policy has grown substantially over the past decade, ${ }^{4}$ which saw the launch of a national social cohesion strategy in $2012 .{ }^{5}$ 'Social cohesion' is now a major outcome in the country's medium-term strategic framework for national development. ${ }^{6}$

Thus far, however, there has been limited empirical research on social cohesion and its relationship to violence in the global South, particularly in new democratic nation-states such as South Africa. Policy and practical interventions by multi-lateral institutions, including the World Bank and the United Nations Development Programme (UNDP), are formulated on the basis of understandings of social solidarity conceptualised in settings such as Europe and Canada.

The few existing academic studies in South Africa have identified a clear need for empirical research on the specific meaning of social cohesion in the South African environment ${ }^{7}$ and have noted the 'scanty and anecdotal' scholarship on the South African social fabric. ${ }^{8}$ On the policy front, a major study in 2011 conducted for the Presidency strongly asserted the need for locally appropriate indicators to measure social cohesion. $^{9}$

'Social cohesion' is a complex and multi-faceted concept, and a significant difficulty tackled by the scholarly research has been to define its scope. ${ }^{10}$ However, most policy and scholarly research focuses on one or several of five dimensions identified by Jenson: (1) the sharing of common values, feelings of belonging; (2) economic inclusion and opportunities to participate in the labour market; (3) participation in public affairs, local and national; (4) tolerance of differences and diversity; and (5) legitimacy of institutions, in particular how well they are able to represent citizens and mediate conflict. ${ }^{11}$

Thus far, most policy and scholarly literature utilises the concept to understand how to integrate all members of the national community into a well-established and relatively cohesive democratic nation-state. However, newly democratised nation-states such as South Africa face a more fundamental challenge: how to establish a socially unified democratic nation-state in the first place, often after individuals and communities have been deeply divided by generations of violence and sociopolitical conflict. This remains a deeply complex and fraught task in post-colonial societies that are in general endemically heterogeneous. In such environments social pluralism may be devalued as a desire to establish national forms of identity, and statehood takes precedence. Vitally, the question of social cohesion in these recently established democratic nation-states is a profoundly political one; it involves establishing the terms of citizenship in a democratic nation-state based on 'fraternity' or community between citizens rather 
than on an authoritarian relationship between state and citizen. ${ }^{12}$

The majority of empirical research attempting to measure social cohesion or advocating a way to measure it employs survey data that are readily available only in the United States (US) and Western Europe, and increasingly, Australasia. More importantly, many indicators used to 'measure' social solidarity currently are premised on notions of 'civic-ness', 'neighbourliness' and 'moral community' that characterise the relatively orderly conditions of society in North America and Western Europe, rather than the far more tenuous conditions of local and national unity in countries such as South Africa.

Here, the most basic legitimacy of state institutions is at stake. Participation may involve immediate defence of life, for example, defending neighbours against violent attack, while a sense of national or even local belonging remains intensely problematic. From this perspective the very meaning of the dimensions of social cohesion that current research attempts to measure may be profoundly different in the global North and South.

In addition, the literature on social cohesion has been shaped by particular theoretical assumptions about the nature of social solidarity and social life.

Durkheim's teleological arguments that as societies modernise, they move from communitarian forms of solidarity to solidarity built around relationships between autonomous individuals, have been particularly influential. The hypothesis of collective efficacy, which is now widely used in criminological theory, influentially defined by Sampson as 'social cohesion among neighbours combined with their willingness to intervene on behalf of the common good', uses data from Chicago in the US and envisages individualised, independent subjects choosing to come together for the good of a particular community. ${ }^{13}$

Yet, in environments such as South Africa where communitarian social relations and identities are still prevalent, such forms of mutual interaction are an assumed part of social life rather than an individual 'choice' in the manner envisaged in Western contractarian thought. As an interviewee in Khayelitsha explained, 'individualism is in the head it is not in the blood'. ${ }^{14}$ These conceptions are strongly linked to the ethics of ubuntu that both implicitly and explicitly structure social life and identity in environments such as South Africa. Ubuntu, an Nguni word, signifies a complex concept that is not easily translated into English but nevertheless has a profound impact on African ontology across the continent. In terms of this ethics, ethical personhood, as opposed to mere existence, is realised through the collective, and by means of actively carrying out duties and obligations to kin and community. ${ }^{15}$

\section{Khayelitsha: a case study}

\section{Methods}

To investigate how social relations and cohesion are understood - and produced - by social actors themselves and to compare this to formal discourses around social cohesion, the research utilised an ethnographic methodology. Ethnography seeks to interpret the meanings located in particular social and cultural systems. ${ }^{16}$ Geertz argues that social actors are suspended in 'webs of significance' that they themselves create and sustain meaningful and stable social relationships with each other because they share those common understandings of reality. ${ }^{17}$

Therefore this research did not attempt a quantitative analysis of violence, social cohesion or the impact of the VPUU intervention on both of these factors. Instead it sought to understand the context of violence and social cohesion in Khayelitsha and the meanings attributed to the VPUU in this milieu.

The fieldwork was carried out by research team member Ncedo Mngqibisa over a period of 10 months. He immersed himself in the communities living in the Harare and Kuyasa sections of Khayelitsha by conducting daily field visits that allowed him to produce a 'thick description'18 of the 'way of being'19 of these communities through semi-structured interviews, focus groups, informal conversations and ongoing systematic observations, which were recorded in field notes. All interactions probed questions about the way in which people do and do not cooperate in Khayelitsha, forms of social and other organisation, the degree of sociality between neighbours, experiences and norms around 
violence, and local responses to violence, including both formal interventions such as the VPUU and informal activities such as community patrols and vigilante action.

Interviewees were identified through a 'snowball sampling' methodology that gave the researcher deepening access to different components of the community. Snowball sampling is particularly useful for accessing 'hidden'20 or more 'vulnerable' and 'impenetrable'21 social groups. The research began with a process of community profiling that involved identifying and interviewing key community leaders from local government, civil society, schools and non-governmental organisations (NGOs). While every effort was made to speak to a range of role players with different perspectives, a snowball sampling approach does introduce the possibility of bias as a result of the fact that the methodology depends on referral from one interviewee to another, who are almost inevitably linked within social or other networks.

The research on the VPUU was constrained by the fact that the HSRC was unable to secure formal cooperation with the intervention, although this was the initial intention of the research project. Therefore this study relies on the perspectives of those who interacted with the intervention and what publicly available documentation we could obtain.

Through a process of engagement with the Khayelitsha community in Harare and Kuyasa, informal traders emerged as a group who had a significant level of engagement with and stake in the VPUU intervention and hence were interviewed systematically, both individually and in a focus group. Another focus group was held with informal traders who are foreign nationals to gain their perspective of informal trading in the township. In addition, focus groups were held with beneficiaries of the VPUU social development programme who had received funding from the organisation for community-based projects, as well as with young entrepreneurs who had been using VPUU facilities such as the 'Hub' business development space. Finally, focus groups were held with young men and young women respectively to draw out the gendered dimensions of violence in Khayelitsha.
Recordings of a total of 58 interviews and six focus groups were translated into English by a professional translator, combined with Mngqibisa's field notes and commentary on the key research issues of the study. The qualitative material was analysed using inductive thematic analysis. This process consists of reading through textual data, identifying themes in the data, coding those themes, and then interpreting the structure and content of the themes. ${ }^{22}$ The analysis also drew on grounded theory, which is a type of inductive thematic analysis. Developed by Glaser and Strauss ${ }^{23}$ grounded theory is a set of iterative techniques designed to identify categories and concepts within texts that are then linked into formal theoretical models. ${ }^{24}$ This method made it possible to 'read' the different sources of data collected against each other in an ongoing recursive analysis.

\section{Social cohesion in Khayelitsha}

Khayelitsha is the country's second largest township. It is characterised by severe levels of violence and poverty. The township experiences some of the highest murder rates in the country, currently at a ratio of between 76 and 108 murders per 100000 of the population at different police stations in the area. ${ }^{25}$ This is well above the national murder rate of 32 murders per 100000 of the population, which is already five times higher than the 2013 global average of six murders per $100000 .{ }^{26}$

The ethnography shows pervasive levels of fear of violence in public and private spaces. A young woman explained that 'we cannot walk outside at night because of the fear. You fear being raped, robbed, I don't know if I will get to where I am going alive or if I will be killed on my way. ${ }^{27}$ Private spaces are also contaminated:

You can't really sleep at night even when you are with the person you are in a relationship with.

During our mothers' and grandmothers' times they felt safe when they were with their men. You only feel safe under your roof and even there you need to lock. You have to sleep with airtime on your phone so you can call for help. ${ }^{28}$

There is also considerable youth gang violence. Residents feel 'robbed by our children that we gave birth to in the township'. ${ }^{29}$ 
Khayelitsha is also marked by substantial economic disadvantage, with the average income of those employed not more than R2 000 per month and half of the population living in shacks or informal dwellings. Khayelitsha was one of the last townships established under apartheid and was intended to forcibly 'consolidate' the settlement of black people in the urban areas of the Western Cape. ${ }^{30}$

Throughout its history it has experienced significant migration, particularly from the largely poor, rural province of the Eastern Cape. Currently about $50 \%$ of the adult population come from this province, although young people below 19 have largely been born in the township. ${ }^{31}$ Khayelitsha has therefore developed from a 'previously planned township area under apartheid into a sprawling, largely informal urban area characterised by a lack of basic services and infrastructure where over-crowding and inadequate living conditions prevail for the vast majority of its residents'. ${ }^{32}$ While high levels of migration do not automatically lead to higher levels of violence, rapid migration, particularly when it is not well managed by the state, can place strains on existing social bonds and local forms of regulation. ${ }^{33}$

The analysis of the ethnographic data shows that Khayelitsha does not experience an absence of social cohesion but, like many South African townships, is characterised by dense informal social networks and multiple forms of social ordering and social organisation, founded implicitly on communitarian ethics and social practice.

I think it's a cultural thing to know everyone. ${ }^{34}$

One of the things most of us grew up with is that the neighbour is also your mom or dad. If your parents are at work, they normally take care of us and play the role of a parent. When celebrating things we do it together as a community. l'd say that if you are living in the township it is hard to say you don't know your neighbour unless if you are new. ${ }^{35}$

Informal traders explain: 'We trust each other. If someone has a problem they can approach the other person for help.' ${ }^{36}$ 'We are tight in this area. ${ }^{37}$ People do intervene on each other's behalf: 'We don't have securities. My security is this one and that one [other traders] ... If we get robbed or I am being robbed, these securities you see here have to come out to help me.' ${ }^{38}$ However, many of these networks are also under pressure. 'People no longer have ubuntu'. 39 Class divisions undermine cohesion: 'Greeting the neighbour is fine, but it is not alright to ask for sugar from a neighbour that is in a higher level than you.' ${ }^{40}$ In addition, 'Western ways of living' are 'influencing people on how they should live'41 and undermining communitarian values and practices.

Although networks can be a source of resilience, they can also be a source of violent exclusion and control, manifested in group violence against a precariously defined 'other'. Here neighbours are extraordinarily willing to intervene on each other's behalf; however, the 'common good' they seek to achieve is often the violent exclusion of the criminal and the momentary restoration of 'order'.

A trader outlined: 'Most of the time, Xosh is not at her stand. The skollies go to Xosh's stand and take whatever they want. I have to stop the fights. If the person runs, they [community members] chase the person with a knife.' ${ }^{42}$ Another trader reiterated that he is prepared to risk his life and face lethal gun violence to defend other traders: 'We don't care about the gun and dying. ${ }^{43}$

Violence is frequently organised as a public spectacle, a performance of moral community, as the following field report of a spontaneous armed gathering at a shop owned by a Chinese national accused of mistreating a worker indicates. 'It was roughly around lunch time when I saw people amalgamated in front of the Chinese 5 Rand store, carrying stones, umbrellas and brooms from the toilets in the mall ... People claimed that Chinese treat their workers [badly] and they ... were singing that they must go back to China. ${ }^{44}$

One of the classic indicators of social cohesion is 'Do you recognise people in your neighbourhood?' People in Khayelitsha 'know' each other but this 'knowing' can be a source of violent retribution. Those who are identified as 'criminals' may be subjected to violent public punishment. A former gang member explained that 'our utmost fear is not going to jail or dying but it's the torture by the community should they find you'. ${ }^{45}$ Those who report crime are known to those 
who commit crime. These individuals often have networks with local police. A female focus group participant explained why she does not report drug dealing: 'I don't report it because I fear for my life ... if I go and report ... at the police station, the police will get to that house and tell on me. ${ }^{46}$

While traditional crime prevention approaches are premised on utilising community knowledge, in this situation 'knowing' can be dangerous. The concept of collective action and a willingness to intervene on behalf of a 'common good', which underpins international definitions of collective efficacy, therefore takes an ambiguous turn in environments where the nature of the common good is profoundly contested and parochial conceptions of it are violently defended. In this setting, citizens often have an ambiguous relationship with the state, law and legality and conventional forms of regulation. For example, one interviewee, referring to constitutional provisions for the rights of women and children, asserted that 'the government has destroyed this country with the laws they set'. ${ }^{47}$ The police occupy a precarious and weak position in this world of informality. A respondent stated in this regard that 'they [police] are defeated'. ${ }^{48}$ Associations of minibus taxi drivers, the main form of transport for many South Africans, play a central regulatory function in Khayelitsha. This emerges from a history of informal regulation and social control that developed in townships as a result of the absence of legitimate governance under apartheid. In many ways taxi associations are a more influential presence than the police, and are well known for their use of coercive force. Taxi drivers act as informal police who 'discipline' young people, act against criminals, even control informal economic relations, and often mete out significant violence. There appears to be at least some sanction for the violence of taxi associations, although the parents of young people alleged to be gang members who are beaten up by taxi drivers do not support their violence. A young schoolgirl argued that 'taxi drivers help reduce the incidences of gang war by fighting fire with fire'. ${ }^{49}$

The violence of taxi drivers is partly a response to the widespread youth gang problem in the township where schoolgoing boys, armed with knives and guns, are shaping the nature and meaning of public space. This includes parks built through urban upgrading, and the institutional space of the school, as this quote illustrates: 'A fight had broken in the boys' bathrooms [at school] and knives were drawn ... so now the boys who drew knives for each other went to their gangs and now it's no longer one on one but gang versus gang. ${ }^{50}$

The gangs impose their own form of policing and social order, which involves the territorial control of space. They overturn generational hierarchies, for example, taking control of the space of the school to pursue gang conflicts and threatening teachers with violence. A schoolgirl emphasised that 'those teachers who don't have cars are in big trouble because they can be attacked easily'. ${ }^{51}$ In a world of deprivation and violence, however, gangs can play an important role in the lives of young men. A gang member outlined his motivations for belonging to a gang: 'It is also wanting to be part of a group of guys who are cool (amajita) because it gives you two things, status and protection. ${ }^{52}$

Therefore, in this setting, localised forms of cohesion that help residents cope with rampant crime and violence through vigilante associations and public violence actually undermine national social cohesion founded on constitutional values, by asserting an alternative, parochial regime of collective justice and punishment that disputes the values and practices of a universal and individualised, rights-based, formal law. The violent expression of this local justice contests the sovereignty of the state, which is ostensibly founded on a monopoly of the use of force in the country.

\section{Violence Prevention through Urban Upgrading (VPUU)}

In order to address some of the challenges of violence and poverty experienced in Khayelitsha, the VPUU initiative was established through a partnership between the City of Cape Town and the German Development Bank in 2004. The intervention aims to reduce violence and improve the quality of life in Khayelitsha. The VPUU is primarily an urban upgrading programme, but it links this to 'work streams' that support social and institutional crime prevention. 
The project endeavours to create a sense of 'place' and ownership of space through aesthetic and practical upgrading interventions that attempt to address the history of Khayelitsha as a mere catchment area for labour under apartheid. In addition, it seeks to provide support for local entrepreneurship, training in the management of facilities and support for community policing. It has made sizeable contributions to infrastructure development, initially in the Harare area of Khayelitsha and increasingly in other areas of the township. It is also being rolled out to a number of other places in the Western Cape.

While the VPUU argues that it is a 'technical' intervention, it is in fact a deeply socially and culturally embedded undertaking, which disrupted, interacted with and shaped existing forms of social relation and social cohesion in the environments in which it was implemented.

The VPUU 'model' draws substantially from international development models, particularly those of UN-Habitat, the World Health Organization (WHO) and, most importantly, the German Development Bank. The bank's model of 'violence prevention through urban upgrading' informs German financial cooperation with countries such as South Africa. This model explicitly seeks to address violence by using 'conventional urban planning tools' and 'coherent and integrated town planning' in order to create an ordered and managed urban environment that bridges 'the divide between the formal and the informal city' and 'stabilise[s] the social environment'. ${ }^{53}$ Urban upgrading in this perspective creates the foundation for new forms of citizenship based on physical and symbolic ownership of space. 'For inhabitants, having an official address means formally being resident of a city', which ostensibly leads to a reduction in violence. ${ }^{54}$ Nonetheless, as Muggah notes in terms of the relationship between violence and urban upgrading, 'the outcomes of slum upgrading are still highly contested with some observers detecting varying socio-economic dividends for the urban poor'. ${ }^{55}$

In addition, cities in the global South are a particularly complex and often deeply informal environment that may not lend themselves easily to traditional approaches of formalisation, regulation and upgrading. Swilling and Annecke note that cities in general are the outcomes of complex interactions of various socio-political, cultural, institutional and technical networks and that the urban environment is often characterised by contradictory processes of routinisation, repetitive crises and transformational practices. ${ }^{56}$ The peculiarities of southern cities are the result of their history of colonialism and postcolonialism, as well as contemporary processes of rapid urbanisation and globalisation. In this environment, 'illegality and informality tug at the normative roots of the state leading to an arena charged with the violence of and toward the governed'. ${ }^{57}$ Consequently, while the traditional urban planning approach to the city foresees the possibility of a significantly planned and regularised environment that could ostensibly 'design out' violence, the empirical 'reality' of most cities, particularly in the global South, involves a range of contradictory practices and processes that make this ideal very difficult to attain, even if it were desirable.

Nevertheless, the image of an 'ordered' city, founded on the model of European and American urbanisation, remains the primary conceptual framing for development interventions such as those funded by the German Development Bank and implemented by the VPUU in Khayelitsha. In this vision of the city, urban planners favour formality, order and modernisation in order to promote an international urbanism that is associated with the vision of a modern city as 'hygienic', sanitary and 'respectable'. Often informality is misunderstood and misrecognised as a result of normative notions of 'rational' economic behaviour and values. ${ }^{58}$ Therefore, while informality may be cast as 'irrational' in these discourses, various types of informality are in fact embedded in a complex of local norms, forms of regulation and sociality that structure daily life in ways that are both meaningful and 'rational'.

The VPUU is fundamentally influenced by these international development policy discourses that seek to create a managed society, characterised by ordered and economised social relations and founded on a normative conception of a formalised city and the self-regulating, economic-rational actor. As a senior VPUU manager explained at the 
Khayelitsha Commission of Inquiry: 'What the programme would like to show over time is the increase in what we would call managed urban areas and the map on the left with the orange dots shows the very few areas that were effectively managed.'59

This is a vision that is profoundly contested by the material reality of informal norms of regulation and control in the fluid space of Khayelitsha, where local colloquial networks often have a far more significant social and symbolic resonance than formal institutional networks. In this context official and 'everyday' networks co-exist and interact with each other, creating overlapping rings of authority and governance in what Shearing and Wood have called the 'pluralization of the governance of security'. ${ }^{60}$

The ethnographic fieldwork evidences some of the struggles by the VPUU to mediate the formal-informal divide and to 'super-impose' a model of order on a deeply contested, informal space. In this space the state is accepted if it provides services, but not if it tries to assert its authority. Here some of the most resonant forms of social regulation are violent and outside the state. Here the lines between what is legal, illegal, criminal or not are blurred, and informal businesses operate according to rationales that do not adhere to normative business practices. In this environment 'scientific' models developed by global organisations struggle to embed themselves in forms of sociality and governance that are far more deeply rooted, and which dispute the normative underpinnings of these interventions.

The VPUU has responded to this challenge by trying to create an explicitly 'apolitical', technical intervention in terms of both who implements (a consulting company) and how the intervention takes place. The initial financing agreement between the German Development Bank and the City of Cape Town stipulated that a 'project-implementing agent' or intermediary, known as the VPUU Consortium, should implement the intervention, led by a team of consultants from Sun Development Pty., which is a subsidiary of a company headquartered in Germany. ${ }^{61}$ The intervention thus avoids direct implementation through existing local government or nongovernmental structures.
The ethnography reveals that while the VPUU characterises itself as 'apolitical' in terms of a lack of allegiance to any particular party, it is deeply invested in regimes of power at both local and city levels. Also, at the same time as the VPUU asserts the 'apolitical' nature of its work in the township of Khayelitsha, the intervention claims and receives notable political support from the City of Cape Town and is institutionally located in the City of Cape Town Mayoral Office, giving it substantial political sanction. The VPUU argues that its 'apolitical' approach has assisted it to achieve community trust in circumstances of high political contestation and anger at lack of government service delivery in Khayelitsha. It is also intended to facilitate equal participation in development without the contamination of political party patronage and is seen to give the intervention the ability to move freely in different environments without being seen as aligned any party or faction. ${ }^{62}$

The VPUU sees social cohesion and social capital as central to its approach. The organisation states that it draws on 'South American models' that focus on the building of community cohesion and social capital. ${ }^{63}$ Social capital, which can be defined as 'networks of social relations that may provide individuals and groups with access to resources and supports' 64 plays a contributory role in building social cohesion. The main means through which the VPUU asserts that it builds social cohesion is community participation in development. It argues that it has engaged in a participatory methodology that 'strives for negotiated solutions in cooperation with communities', which it sees as having been a crucial success factor for the intervention that has helped build social cohesion in Khayelitsha. ${ }^{65}$

However, Piper has called the form of community consultation that the VPUU engages in and the forums it creates as 'designed' in ways that allow for a very limited form of direct citizen participation in democratic decision-making. ${ }^{66}$ Instead, what is created is a representative democracy model led by a cohort of 'responsible' leadership designated and socialised by the VPUU, whose function is to ensure the interests of the project by representing 
stakeholders chosen by the VPUU, rather than being directly accountable to the general citizenry.

One of the key citizen engagement tools that the VPUU uses is baseline surveys, which the organisation discursively constructs as giving a 'voice' to 'ordinary' citizens through a random sample. Therefore, 'although one person in 10 speaks, what they say will be an accurate reflection of what everyone living there would say'. ${ }^{67}$ This is an ostensibly neutral manner of collecting all 'voices': 'it's a way of ensuring that we get an opinion which is independent of any other kind of gate keeping structures or political affiliations which are in place, so that the voice of the community can emerge'. ${ }^{68}$ However, what can be 'said' in a survey is already pre-determined. Which communities can emerge in this putatively 'apolitical' space is also unclear. The baseline surveys that the VPUU conducts collect largely demographic information, which is valuable in its own right but cannot be claimed as a means of giving 'voice' to citizens and is far removed from the type of deliberative voice that Habermas envisaged in his model of a public sphere, that is, 'an arena in which individuals participate in discussions about matters of common concern'. 69

In order to avoid the contestation and patronage of local politics, the VPUU therefore creates its own parallel, managed governance spaces oriented to ensure the delivery of development objectives through controlled community participation. However, as a 'community participation work-stream manager' acknowledged, a major challenge in establishing the organisation's structures at local level has been trying to explain to communities why the VPUU is setting up completely new representative structures. ${ }^{70}$

The major decision-making forums for the project at local level are Safe Node Area Committees (SNAC). the VPUU argues that these are more representative and democratic than current local governance structures, allowing for the equal participation of a range of stakeholders. The SNAC is thus made up of $50 \%$ of stakeholders coming from local government structures and 50\% from community-based organisations, NGOs and faith-based organisations. The VPUU conducts an audit in a particular area and interviews the leadership of organisations to decide who should participate in the structure, based on a range of criteria. Establishing such structures under the tutelage of the VPUU is intended to prevent any one stakeholder from gaining too much power over the development process and to avert the real threat that development processes might be captured for party political or other narrow interests.

In as much as the VPUU seeks to manage who will participate in its 'decision-making' structures, its implementation is steeped in a managerialist discourse and practice that will only acknowledge those citizens who conform to these norms; i.e., the classic neoliberal, self-governing, 'responsible' citizen. One example of this is the set of procedures that must be followed by Community Policing Forums (CPFs) in order to receive financial support from the VPUU. Modelling its contractual relationship with CPFs on formal business conventions, the organisation seeks to conclude 'service level agreements' with CPFs that involve a number of pre-conditions, including that each CPF must have 'accurate data about their membership and who is active and where they are active' (own emphasis). ${ }^{71}$ Secondly, each active member of a neighbourhood watch must submit an incident report at the end of their duties. In addition, each CPF must enter into a 'development contract' with individual volunteers. ${ }^{72}$ 'Standards' have to be agreed to on each of these tasks and 'if the CPF performs to standard they get the money into their account'. ${ }^{73}$ However, when questioned about the success of these contracts with CPFs, a senior VPUU manager acknowledged that 'up until now only the Harare CPF has actually received payments so it's not something that has been that successful up until now' ${ }^{74}$

In contrast to this ideal procedural model that the VPUU seeks to realise, is an example of what is seen as 'inappropriate' behaviour. It was recorded in a neighbourhood watch report, but is in fact a mundane form of interaction in the environment of Khayelitsha:

Incident report: 'We met $\mathrm{X}, \mathrm{Y}$ and $\mathrm{Z}$, they were carrying big stones. We asked them why. The people started swearing and shouting at us and throwing the stones at us. We started throwing the stones back at them. $X$ was hit and fell down. We called a van to check on him.'75 


\section{Informal traders}

A pivotal site where tensions have emerged between the formality that the VPUU seeks to create and local practices of informality, relates to contestation around the creation of formal kiosks for trading by the VPUU.

The VPUU seeks to create a classic Western 'entrepreneur' - the self-interested, utility-maximising individual whose major rationale is the generation of profit. Therefore, the formalisation that the VPUU wants to achieve as the basis of a more 'ordered' and controlled urban environment is not simply about infrastructure but about creating citizens with a particular subjectivity, which is contested by traders' existing norms, world views and forms of social practice. As one trader noted: 'We do want development, we do want the good and glamorous things, but the VPUU needs to know the people they are bringing this development to. ${ }^{76}$

The VPUU therefore enforces a range of business principles and practices that are seen as alien and exclusionary. 'They come with a list of criteria'; ${ }^{74}$ 'they tell you that your business should have a business account and business plan ... their requirements keep you out'. ${ }^{77}$ At the same time the VPUU is itself seen to be engaging in 'business' rather than development as a result of the fact that charges are levied for the use of its facilities.

While on the one hand the kiosks the VPUU has built provide important services, e.g. access to water, electricity and storage space, at the same time the initiative is seen as undermining pre-existing relationships of sociality and reciprocity that underpinned survivalist businesses, where relations between traders were governed horizontally and informally. 'tt's better to sell different things. Business will not go well if you all sell the same thing. That is the guideline.' 'Each person knows their spot. We have rules. You know your place. ${ }^{78}$ Myers argues in this vein that the integration of social networks and patterns of sociality into structured formal forms of urban development can be a poor substitute for previous forms of economic reciprocity and sociality. ${ }^{79}$ In this context, formality can constitute a threat to social networks and patterns of sociality, and render the benefits derivable from it 'doubtful or uncertain'. ${ }^{80}$
In return for the infrastructure it has built, the VPUU enforces a contractual relationship with traders who now occupy these spaces. Many of these traders previously traded 'in the sand' 81 where the VPUU buildings are now located.

The VPUU seeks to establish new forms of ownership of space, in line with classic Crime Prevention through Environmental Design (CPTED) principles that theorise the link between urban space and crime in terms of the notion of 'territoriality', i.e. the concept that a sense of ownership of and responsibility for space can help reduce crime. However, it is exactly this ownership of space that is contested by traders. While some traders acknowledge that the VPUU did engage in consultative processes before the intervention was implemented, the organisation is still seen as having appropriated space that traders were already invested in. This space is now literally and symbolically owned and controlled by the VPUU: 'The place they put up the building is the place we used to work from.' 'They forget that we were trading here.' 82 Informal traders who currently occupy the kiosks that the VPUU has created did not pay for the land on which they traded previously, and maintain that they felt a sense of proprietorship and autonomy. Now they have to pay rent of R900 per month and are subject to a new regulatory regime imposed by the VPUU, which designates what and how they trade. The organisation is therefore seen to have usurped space previously utilised by traders, without external rule or regulation: 'Keep in mind that they build in your spot with your business not registered. ${ }^{183} \mathrm{~A}$ number of traders are now severely indebted. Most seem to have understood that some payment would be needed in compensation for the facilities, but allege they were not aware of how high rents would be. As one female trader elucidated: 'The VPUU brings development, but they don't tell us the price. ${ }^{84}$ The VPUU is seen by some traders to be callously enforcing a contractual relationship. 'They say, "This is not charity."'85

They just tell us, 'vacate if you cannot afford. We have a list of people that want to move in.' ... if you cannot afford to pay rent because there is no business they tell you about moving out. You 
will leave and go stay at the location and what will you eat? ${ }^{86}$

While the VPUU argues that it seeks to understand the 'voice' of citizens through its baseline surveys, interviews with traders appear to reveal a profound struggle to be heard: 'We talked and gave up.' 87 'They don't sit down and talk to the people they found here to find solutions.' 88 'They just come to us only to tell us what they have decided to do.' ${ }^{89}$ 'That affects you as the person who has been here.' 90

The rent charged to traders is in line with the methodology outlined by the German Development Bank that contends that "upgrading can be affordable when carried out jointly. Programmes show that even low-income residents are willing to pay for infrastructure services in adequate conditions.' 91 The VPUU echoes this in its own assertions that 'long term financial sustainability is central to the VPUU approach - to create and develop facilities and systems that are affordable and will pay for themselves. ${ }^{\prime 2}$ In its semi-annual progress report of 2013, the VPUU notes the achievement of a 'milestone' as the fact that 'rental income has for the first time exceeded basic maintenance costs'. ${ }^{33}$ However, affordability appears to be a critical issue in terms of both access to facilities and the rental cost of trading kiosks.

In this setting, attempting to formalise the urban space through urban upgrading, while beneficial, may disrupt complex social networks and have unintended consequences. The question is, how is it possible to fashion violence prevention initiatives around social cohesion that take these complex social networks into account, and that utilise existing community resources and conceptions of social solidarity?

\section{Conclusion}

It is evident that the relationship between social cohesion and violence plays out in multifaceted ways in contexts such as Khayelitsha, disputing some of the assumptions in international interpretations of social cohesion and collective efficacy. Nevertheless, social cohesion is relevant to understanding the conditions of both solidarity and violence in a city in the global South such as Khayelitsha. It is widely used in policy discourse both locally and internationally, has generated a body of scholarship, and most importantly, is shaping the way in which violence prevention is being understood and implemented. This article has therefore sought to interrogate the applicability of international conceptions of social cohesion and its relation to violence in an environment such as Khayelitsha. For all its limitations and definitional fluidity, social cohesion as a conceptual category that tries to capture some of the conditions of cohesion and citizenship in the nationstate, does have analytical and practical value. It grapples with a fundamental question about how societies can cohere in ways that support non-violent forms of local and national democratic unity in a manner that does not stifle contention and embraces and mediates social pluralism.

However, the way in which solidarity has been conceptualised in dominant discourses may be limited by presuppositions about the nature of social, political and economic life typical of the milieu in the global North. The concept therefore needs to be interrogated and recalibrated to take into account what Bourdieu calls the 'habitus' of citizens in the global South, i.e. their lifestyle, values, outlooks and expectations, their specific subjectivities, their forms of identity and their mutual relations. ${ }^{94}$ All these, often operating as 'common sense' ways of being, determine social practice far more powerfully than externally imposed norms.

Thus, in Khayelitsha communitarian world views support forms of mutual sociality that are intrinsic to social life and identity. These are underpinned implicitly by the philosophy of ubuntu in which personhood is achieved through social relations rather than through individual empowerment. However, these communitarian networks and 'ways of life' are under social and structural strain and moreover are the conduits not only for reciprocity, but also for violence. This is an environment where citizens intervene on each other's behalf, as in Sampson's concept of collective efficacy, but frequently in order to enact what are seen as defensive forms of violence in a situation of considerable disorder, rather than to oppose violence. Informal networks are not channels for middle class forms of sociality such as the bowling clubs that Putnam envisaged, but instead function as vital regulatory mechanisms for social, economic and 
political life in an environment where the state in general, and the police in particular, can be substantively absent as meaningful governing agents.

These conditions of informality, plurality and violence pose difficult questions for violence prevention efforts that seek to build non-violent forms of cohesion. What this research has revealed, however, is the ubiquitousness of community networks and world views that conceptually and practically support intervention and solidarity, and which could be mobilised for violence prevention. This is not to say that violence does not remain an authoritative source of power in private and public life and social networks.

In this environment, an internationally conceptualised and funded intervention such as the VPUU attempts to avoid engaging with the 'irregularity' of the social and political environment. It instead insists on normative practices and subjectivities, as well as its own governance spaces and regulatory mechanisms, implicitly shaped by an assumption of their superiority. Citizens are delivered a 'model' that they did not substantively help formulate and are 'allowed' to participate on terms that are already set. However, attempts to 'ignore' the society in which the organisation is embedded in order to effect an ostensibly technical and neutral intervention founders on the unavoidable fabric of society in which the programme is embedded, limiting its ability to recognise and build on existing forms of social cohesion and communitarianism and to form a genuinely equal partnership for the prevention of violence.

To comment on this article visit

http://www.issafrica.org/sacq.php

\section{Notes}

1 R Putnam, Bowling alone, New York: Simon/Schuster, 2000.

2 DM Fetterman, Ethnography: step by step, $3^{\text {rd }}$ ed., Applied Social Research Methods Series, vol. 17, Los Angeles: Sage, 2010.

3 RJ Sampson, SW Raudenbush and F Earls, Neighborhoods and violent crime: a multilevel study of collective efficacy, Science, 277, 1997, 918-924.

4 See The Presidency, Republic of South Africa, Social cohesion \& social justice in South Africa, Pretoria: Policy Co-ordination and Advisory Services, 2004; The Presidency, Republic of South Africa, A nation in the making: a discussion document on macro-social trends in South Africa, Pretoria: Policy Co-ordination and Advisory Services, 2006; The Presidency, Republic of South Africa, Towards a fifteenyear review, Pretoria: Policy Co-ordination and Advisory Services, 2008; The Presidency, Republic of South Africa, National Development Plan: Vision for 2030, Pretoria: National Planning Commission, 2011.

5 Department of Arts and Culture, Republic of South Africa, !ke e: /xarra //ke: creating a caring and proud society, a national strategy for developing an inclusive and a cohesive South African society, 2012.

6 The Presidency, Republic of South Africa, Medium term strategic framework 2014-2019, 2014.

7 D Chisdester, P Dexter and PW James, What holds us together?, Cape Town: HSRC Press, 2003.

8 I Chipkin and B Ngqulunga, Friends and family: social cohesion in South Africa, Journal of Southern African Studies, 34:1, 2008, 61-76.

9 J Struwig et al., Towards a social cohesion barometer for South Africa, University of the Western Cape, Research Paper, 2011.

$10 \mathrm{~J}$ Jensen, Defining \& measuring social cohesion, Commonwealth Secretariat and United Nations (UN) Research Institute for Development, Social Policies in Small States Series, 1, Thematic Paper, 2010; R Berger- Schmitt, Considering social cohesion in quality of life assessments: concepts and measurement, Social Indicators Research, 58:3, 2002, 403-428; J Chan, HP To and E Chan, Reconsidering social cohesion: developing a definition and analytical framework for empirical research, Social Indicators Research, 75, 2006, 273-302; D Brisson and CL Usher, Conceptualizing and measuring bonding social capital in lowincome neighbourhoods, Journal of Social Service Research, $34: 1,2007,1-11$.

11 J Jensen, Mapping social cohesion: the state of Canadian research, Canadian Policy Research Network (CPRN), Study No. F/03, 1998; P Bernard, Social cohesion: a critique, CPRN, Discussion Paper No. F/09, 1999; A Kearns and R Forrest, Social cohesion and multi-level urban governance, Urban Studies, 37, 2000, 995-1017.

12 Chipkin and Ngqulunga, Friends and family; E Balibar, Outlines of a topography of cruelty: citizenship and civility in the era of global violence, Constellations, 8:1, 2001, 15-29.

13 Sampson, Raudenbush and Earls, Neighborhoods and violent crime, 918.

14 Interview report, parent, Ncedo Mngqibisa, Khayelitsha, March 2014.

15 N Bohler-Muller, The story of an African value, SA Public Law, 20:2, 2005, 266-280; IA Menkiti, Person and community in African traditional thought, in RA Wright (ed.), African philosophy: an introduction, Lanham: Rowman \& Littlefield, 1984.

16 WH Goodenough, Multiculturalism as the normal human experience, Anthropology \& Education Quarterly, 7:4, 1976, $4-7$.

17 G Geertz, The interpretation of cultures: selected essays, New York: Basic Books, 1973, 5.

18 Ibid., 6.

19 Fetterman, Ethnography, 65 
20 MJ Salganik and DD Heckathorn, Sampling and estimation in hidden populations using respondent-driven sampling, Sociological Methodology, 34:1, 2004, 193-239.

21 University of Surrey, Social Research Update, 33, Summer 2001.

22 G Guest, KM MacQueen and EE Namey, Applied thematic analysis, Thousand Oaks: Sage, 2012.

23 BG Glaser and AL Strauss, The discovery of grounded theory, New Jersey: Transaction Publishers, 1967.

$24 \mathrm{~J}$ Corbin and AL Strauss, Basics of qualitative research: techniques and procedures for developing grounded theory ( $3^{\text {rd }}$ ed.), Thousand Oaks: Sage, 2008.

25 Institute for Security Studies (ISS), Crime Hub.

26 ISS Crime Hub, Fact sheet: Explaining the official crime statistics for 2013/14, 19 September 2014.

27 Focus group transcript, young women, Ncedo Mngqibisa and Dineo Seabe, Khayelitsha, October 2014.

28 lbid.

29 Focus group transcript, informal traders, Ncedo Mngqibisa, Khayelitsha, September 2014.

$30 \mathrm{~J}$ Seekings, Economy, society and municipal services in Khayelitsha, Report for the Commission of Inquiry into Allegations of Police Inefficiency in Khayelitsha and a Breakdown in Relations Between the Community and the Police in Khayelitsha, Centre for Social Science Research, University of Cape Town, 2013.

31 Ibid.

32 L Ugur, Beyond the pilot project: towards broad-based integrated violence prevention in South Africa, Technische Universität Darmstadt, 2014, 118

33 J Beall, B Guha-Khasnobis and R Kanbur, Urbanization and development in Asia: multidimensional perspectives, New Delhi: Oxford University Press India, 2012.

34 Focus group transcript, young entrepreneurs, male respondent, Ncedo Mngqibisa and Diana Sanchez, the Hub, Khayelitsha, October 2014.

35 Focus group transcript, young entrepreneurs, female respondent.

36 Focus group transcript, informal traders, female respondent

37 Focus group transcript, informal traders, male respondent.

38 Focus group transcript, informal traders, male respondent.

39 Focus group transcript, older men, Ncedo Mngqibisa, Khayelitsha, October 2014.

40 Focus group transcript, older women, Ncedo Mngqibisa, Khayelitsha, October 2014.

41 Focus group transcript, young entrepreneurs, male respondent.

42 Focus group transcript, informal traders, female respondent.

43 Focus group transcript, informal traders, female respondent.

44 Field report, Ncedo Mngqibisa, Khayelitsha, April 2014.

45 Interview report, two former gang members, Ncedo Mngqibisa, Khayelitsha, March 2014.

46 Focus group transcript, older women.

47 Focus group transcript, older men.

48 Focus group transcript, informal traders, male respondent.
49 Interview report, Ncedo Mngqibisa, two schoolgirls, Khayelitsha, March 2014.

50 Field report, Ncedo Mngqibisa, Khayelitsha, February 2014.

51 lbid.

52 Interview report, two former gang members.

53 KfW Entwicklungsbank, Violence prevention through urban upgrading: experiences from financial cooperation, 2010.

54 Ibid

55 R Muggah, Researching the urban dilemma: urbanization, poverty and violence, International Development Research Centre (IDRC), 2012, 62.

56 M Swilling and E Annecke, Just transitions: explorations of sustainability in an unfair world, Cape Town: Juta Books, 2011.

57 V Rao, Slum as theory: the South/Asian city and globalization International Journal of Urban and Regional Research, 30:1, 2006, 225-232, 229.

58 D Neves and A du Toit, Money and sociality in South Africa's informal economy, Africa, 82:1, 2012, 131-149.

59 C Giles, Transcript of public hearing, Commission of Inquiry into Allegations of Police Inefficiency in Khayelitsha and of a Breakdown in Relations between the Community and the Police in Khayelitsha, 12 February 2014.

60 C Shearing and J Wood, Nodal governance, democracy, and the new 'denizens', Journal of Law and Society, 30:3, 2003, 400-419, 403.

61 Ugur, Beyond the pilot project, 127.

62 Ibid

63 Giles, Transcript of public hearing.

64 Policy Research Initiative (PRI), Social capital as a public policy tool: project report, Ottawa: Government of Canada, 2005.

65 Violence Prevention through Urban Upgrading (VPUU), Semiannual progress report no. 4: January to June 2013, VPUU phase 3, 2013, 2.

66 L Piper, Development trustees not rent-seeking deployees: the designed meaning of community participation in the Violence Prevention through Urban Upgrading Project (VPUU) in Cape Town, South Africa, unpublished paper, 2012.

67 VPUU, BM/France Section informal settlement upgrade baseline survey: Khayelitsha, Cape Town - November 2010, 8.

68 Giles, Transcript of public hearing.

69 ME Warren, Can participatory democracy produce better selves? Psychological dimensions of Habermas's discursive model of democracy, Political Psychology, 14:2, Special Issue: Political Theory and Political Psychology, 1993, 209-234, 212.

70 Ugur, Beyond the pilot project, 139

71 Giles, Transcript of public hearing.

72 lbid., 2757

73 lbid., 2758.

74 lbid., 2759.

75 Focus group transcript, informal traders, female respondent.

76 Focus group transcript, informal traders, male respondent.

77 Focus group transcript, informal traders, female respondent. 
78 Group interview transcript, Ntlazane traders association, Ncedo Mngqibisa, March 2014.

79 G Myers, African cities: alternative visions of urban theory and practice, London: Zed Books, 2011.

80 Neves and Du Toit, Money and sociality in South Africa's informal economy, 142.

81 Focus group transcript, informal traders.

82 Group interview transcript, Ntlazane traders association, Ncedo Mngqibisa, March 2014.

83 Focus group transcript, informal traders, female respondent.

84 Ibid.

85 Individual interview transcript, informal trader, Khayelitsha, March 2014.

86 Group interview, Ntlazane traders association.

$87 \mathrm{lbid}$

88 Focus group transcript informal traders, male respondent.

89 Group interview, Ntlazane traders association.

90 Focus group, informal traders, male trader.

91 KfW Entwicklungsbank, Violence prevention through urban upgrading.

92 M Krause in KfW Entwicklungsbank, Violence prevention through urban upgrading, 098.

93 VPUU, Semi-annual progress report no. 4.

94 P Bourdieu, Distinction: a social critique of the judgement of taste, Massachusetts: Harvard University Press, 1984. 